\title{
The impact of perceived gender bias on obstetrics and gynecology learning experience among medical interns
}

\author{
Dhananjaya B. $S^{1}$, Venkatesh. $P^{2, *}$, Rajesh. $S . S^{3}$ \\ ${ }^{1}$ Professor and Head, Dept. of Obstetrics \& Gynecology, ${ }^{2}$ Associate Professor, ${ }^{3}$ Assistant Professor, Dept. of Community \\ Medicine, Sri Siddhartha Medical College, B.H. Road Tumkur, Karnataka, India \\ *Corresponding Author: \\ Email: vepa77@gmail.com
}

\begin{abstract}
Introduction: There is gender bias in teaching and learning Obstetrics and gynecology to undergraduates and studies have shown that mostly male students describe educational inequities. We wanted to explore the effect of the students' gender on their perception of quality and quantity of teaching, the amount of experiential learning, and their interest in obstetrics and gynecology.

Materials and Methods: A cross-sectional mixed method approach wherein 96 internees (both lady interns and male interns) who had completed the OBG posting after taking their written informed consent, were given 18 point anonymous questionnaire comprising items about their learning experience and procedures. Two focus group discussions of 12 internees, who were grouped into girls and boys group, was conducted. The data was analyzed using Fischer exact test at 5\% significance level. All the responses of FGD were transcribed, coded, grouped together into different themes and analyzed.

Results: Female interns conducted more number of deliveries compared to males. Patients' refusal to give history was statistically significant for males than females. Male interns were significantly less confident with managing gynecological problems compared to females. FGD revealed that patient factors like religion, better educational status, higher socio-economic level \& people around the interns like postgraduates and nurses, sought female preference and also refusal from patients' side.

Conclusion: All these factors led to discrimination for male interns to learn and choose OBG as career.
\end{abstract}

Keywords: Gender bias, Impact, Learning experience, Undergraduates.

\section{Introduction}

Obstetrics and Gynecology is a very sensitive subject in the sense that we are dealing with the private parts of the feminine body. In this context, women are concerned about their care provider's gender while seeking cares in order to ensure privacy and comfort. There is some gender bias in teaching and learning Obstetrics and gynecology to undergraduates ${ }^{1}$ and also during acquisition of other clinical experiences across both the genders. ${ }^{2}$ Male interns may have different perceptions and learning experiences compared to female interns affecting their learning. ${ }^{3}$ Studies show that patients' preferences along with the organizational forces playing into the consumers' preferences by propagating female physicians to female patients also play a role in reinforcing the perception that women tend to be more accepting of female than male medical students for participating in intimate examinations. ${ }^{4}$ This may affect their future practice as well as their decisions of selecting post graduate program. It is crucial that we examine gender bias in obstetrics and gynecology training and practice, and consider how it affects men both in learning obstetrics and gynecology and considering it as a career. Hence we started the study with the objectives to explore the effects of the intern's gender on their perception of quality and quantity of teaching-learning experience. Also to identify the perceptions of how their gender affect their acquisition of skills during their obstetrics and gynecology clerkship.

\section{Materials and Methods}

All 96 Interns who were doing as well as those who had completed Obstetrics and Gynecology clerkship in the Department of Obstetrics and Gynecology in the month of September 2015, agreed to participate in the study. The study was conducted in Department of Obstetrics \& Gynecology, Sri Siddhartha Medical College, Tumkur. Here a mixed method cross-sectional approach study design was used. In the Quantitative study, after taking informed consent, a questionnaire looking at their learning experience, had been administered. The learning experiences of interns were captured as variables like cases seen, history presented with speculum and vaginal examination. Patient refusal was an independent factor external to the intrinsic learning of the interns. These sub categories were assigned equal weights, grouped and analyzed. The study was approved by Institutional Ethics Committee, Sri Siddhartha Medical College, Tumkur.

To further investigate the perceptions of gender and its role in influencing the learning in obstetrics and gynecology, a focus group discussion ${ }^{5}$ of 12 interns was conducted. Here 6 male and 6 female interns consented to participate wherein FGD checklist was used to get their responses across various aspects of their learning, presence of people and their types, patients' preferences, opportunity to perform the tasks in the clerkship period. 


\section{Statistical Analysis}

The data obtained from questionnaire was entered in to Microsoft Excel sheet, and test of significance was calculated using Chi-square Test and Fischer exact test using SPSS software version 16.0. The responses from Focus group discussion were presented as textual information

\section{Results}

Table 1: Distribution of the various learning outcomes across male and female interns

\begin{tabular}{|c|c|c|c|}
\hline Variables & Male: $N=34$ & Female: $N=62$ & P value \\
\hline $\begin{array}{l}\text { Cases seen } \\
<20 \\
>20\end{array}$ & $\begin{array}{c}6 \\
28 \\
\end{array}$ & $\begin{array}{c}6 \\
56 \\
\end{array}$ & 0.208 \\
\hline $\begin{array}{l}\text { Cases presented } \\
<5 \\
>5\end{array}$ & $\begin{array}{c}26 \\
8\end{array}$ & $\begin{array}{l}48 \\
14\end{array}$ & 0.553 \\
\hline $\begin{array}{l}\text { Vaginal examination conducted } \\
<10 \\
>10\end{array}$ & $\begin{array}{l}23 \\
11\end{array}$ & $\begin{array}{l}29 \\
33\end{array}$ & 0.038 \\
\hline $\begin{array}{l}\text { Speculum examination } \\
<10 \\
>10\end{array}$ & $\begin{array}{l}19 \\
15\end{array}$ & $\begin{array}{l}25 \\
37 \\
\end{array}$ & 0.197 \\
\hline $\begin{array}{l}\text { History taking } \\
<10 \\
>10\end{array}$ & $\begin{array}{l}13 \\
21 \\
\end{array}$ & $\begin{array}{l}29 \\
33 \\
\end{array}$ & 0.278 \\
\hline $\begin{array}{l}\text { Patient Refusing Presence } \\
\text { YES } \\
\text { NO }\end{array}$ & $\begin{array}{l}16 \\
18\end{array}$ & $\begin{array}{l}18 \\
18\end{array}$ & 0.475 \\
\hline $\begin{array}{l}\text { Patient Refused To Give History } \\
\text { YES } \\
\text { NO }\end{array}$ & $\begin{array}{c}8 \\
26\end{array}$ & $\begin{array}{l}01 \\
61\end{array}$ & 0.001 \\
\hline $\begin{array}{l}\text { Patient Refused To Give Consent } \\
\text { for PV/PS } \\
\text { Yes } \\
\text { No }\end{array}$ & $\begin{array}{l}20 \\
14\end{array}$ & $\begin{array}{l}36 \\
26\end{array}$ & 0.559 \\
\hline $\begin{array}{l}\text { Gender Status Has Affected Your } \\
\text { Learning Experience } \\
\text { Yes } \\
\text { No }\end{array}$ & $\begin{array}{l}09 \\
25\end{array}$ & $\begin{array}{l}12 \\
50\end{array}$ & 0.289 \\
\hline $\begin{array}{l}\text { Difficulty in dealing With } \\
\text { Gynecological Problems } \\
\text { Yes } \\
\text { No }\end{array}$ & $\begin{array}{c}25 \\
9\end{array}$ & $\begin{array}{c}61 \\
1\end{array}$ & 0.001 \\
\hline $\begin{array}{l}\text { Equal opportunity } \\
\text { Yes } \\
\text { No }\end{array}$ & $\begin{array}{c}26 \\
8\end{array}$ & $\begin{array}{c}59 \\
3\end{array}$ & 0.009 \\
\hline $\begin{array}{l}\text { OBG as career } \\
\text { Yes } \\
\text { No } \\
\text { Neutral }\end{array}$ & $\begin{array}{l}13 \\
18 \\
3\end{array}$ & $\begin{array}{c}31 \\
25 \\
6\end{array}$ & 0.482 \\
\hline $\begin{array}{l}\text { Learning experience* } \\
\text { Low } \\
\text { Better }\end{array}$ & $\begin{array}{l}17 \\
17 \\
\end{array}$ & $\begin{array}{l}27 \\
35 \\
\end{array}$ & $\mathrm{p}>0.05$ \\
\hline $\begin{array}{l}\text { Patient's response as factor for } \\
\text { learning experience\# } \\
\text { Refusal } \\
\text { Non-refusal }\end{array}$ & $\begin{array}{l}15 \\
19\end{array}$ & $\begin{array}{l}18 \\
44 \\
\end{array}$ & $\mathrm{P}>0.05$ \\
\hline
\end{tabular}

* Chi-square test=0.368147 df =1; \# Chi-square test=0.136633 df =1 
There was significant difference was found across the male and female interns in conducting more vaginal examinations $\{32.4 \%$ vs $53.2 \%\} \quad(\mathrm{P}=0.038)$, dealing with the gynecological problems of the patients and opportunity given to them $(\mathrm{P}=0.009)$ during their learning experience respectively. Female interns were having difficulty in dealing with these gynecological problems significantly $(\mathrm{P}=0.001)$. But it could be ascribed to the point that the patients reported to those female interns more often than to male intern (male $23.5 \%$ vs female- $1.6 \%$ ) $(\mathrm{P}=0.001)$ (Table. 1$)$
Across the patient-wise factors, refusal of the patients to give history of their problems was found to be significant external factor across male and female but while giving the consent for the speculum examination, there was no difference noted.

Further analysis found that there was no significant difference between male and female interns with regard to learning experience and also with patient's refusal to their presence or during examination.

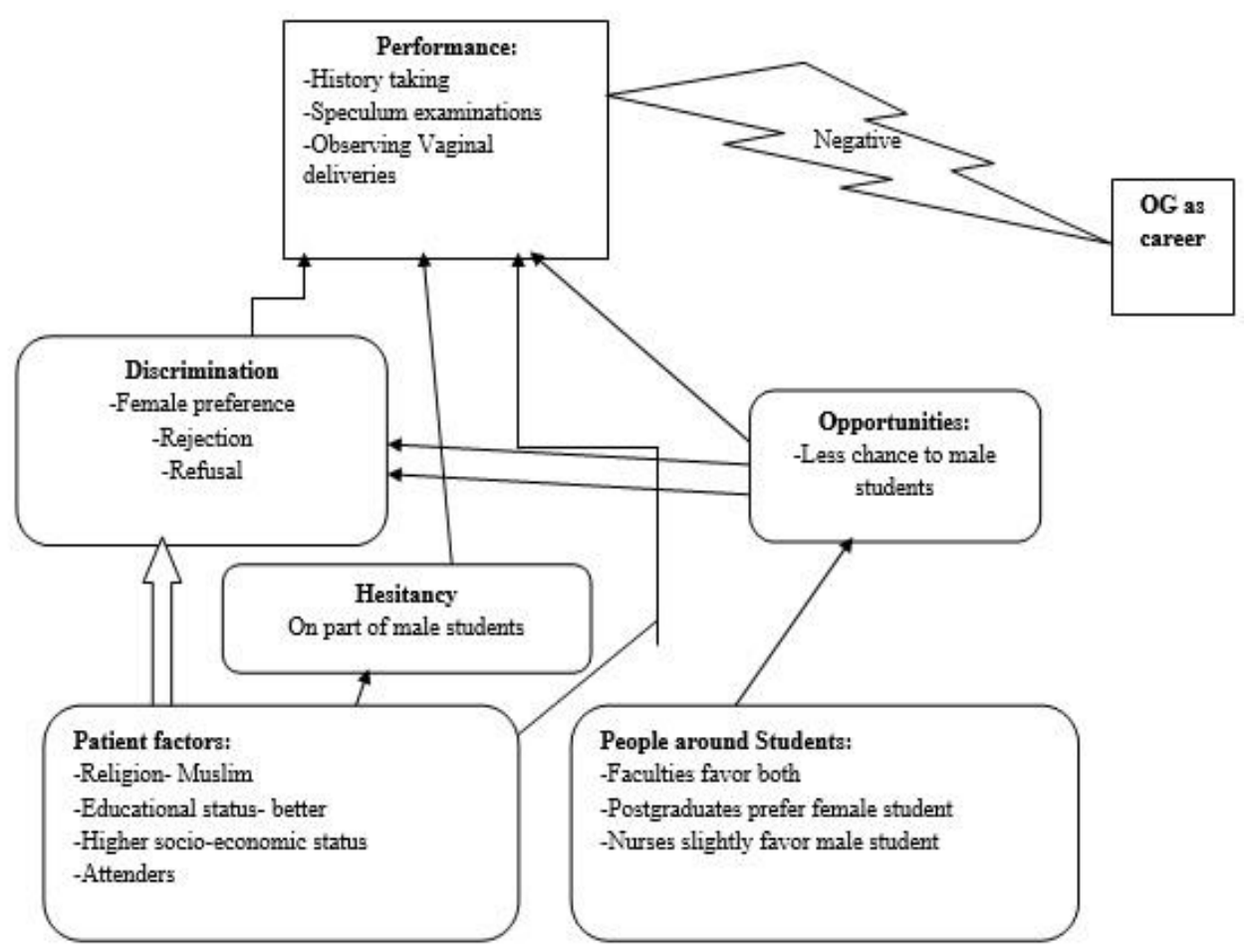

Fig. 1: Flow of factors that influence the gender preference among the interns

The focus group discussion was conducted among equal number of interns across both the genders. It revealed various influencers upon the learning of the interns during their clerkship in the Obstetrics. Predominantly among them were patient related factors, people surrounding interns and bias from the patient side. Among elements of bias which were captured, refusal of patient to give history, rejection of some patients to male interns had been more observed. However in terms of procedures and deliveries both Male and Female group expressed less exposure of cases more often reported by latter. Male interns reported reluctance from Muslim patients to get interviewed.

Whereas no such marked difference was observed across both the intern's groups during interaction with patients from urban residents and better educated ones.

This influenced the male interns to hesitate and underperform during their clerkship. This experience has led the male intern to decide against choosing
Obstetrics as a career. Postgraduates' presence was denoted as a hindrance to both the interns' groups with regard to exposure.

\section{Discussion}

Vaginal and speculum examination conducted, history taking and case presentation as well the opportunity to do the procedures were considered objective measures and deterministic of the learning experience.

There was no difference across both genders of interns in terms of exposure to obstetrics \& gynecology cases except the internal pelvic examination which was found to have significant difference [Female- $53.2 \%$ vs Male-32.4\%]. Similar observation was found in two studies [22\% Female vs $15 \%$ Male] by O' Flynn \& Janice Rymer ${ }^{6}$ and Heidi Powel \& Janis Bridge study [Female $-81 \%$ vs Male-59\%]. ${ }^{7}$ Being male or female could affect their learning and the study found that there was no difference in their learning experience 
across both genders. However with regard to the opportunity of performing procedures, female interns had better chance than their male counterparts as found in another study of gender preference [female-22\%; male- $0.2 \%] .^{3}$

Patients' preferences played a significant role in deciding the gender of the care provider. In the study, patients preferred female interns for giving details of their complaints [Female- 8 vs Male-1] but while giving the consent for doing internal pelvic examination did not find such difference in acceptance across male and female interns. O'Flynn and Rymer demonstrated that, among their gynecology clinic population, 33\% of women refused to see any student, $42 \%$ accepted any student, and 25\% would accept a female student for clinical examination. ${ }^{6}$ Patients' refusal to get examined by male interns was observed in our study which was also observed in $50 \%$ of the subjects in another study. ${ }^{8}$ Patients preferred female medical students for examination in a study about gender preference. ${ }^{3}$ However patients did not refuse to consent for the internal pelvic examination to interns across both the genders. By combining all these factors, study found that there was no significant difference in the learning experience as well as the patient's refusal across interns both the genders.

The focus group discussion of the study revealed that patient related factors, surrounding people in the training, bias and the performance were determinant in influencing the learning experience. There was less opportunity to perform procedures led to hesitancy among male interns which led to reduced exposure to performance and their skills. The central aspect of learning-the performance of the interns was compounded by female preference by the patients, ${ }^{3}$ their refusal and religious status.

Postgraduate's presence was observed to be a deterrent while presence of nursing staff was found to be facilitative, as reported by male interns. Presence of faculties and coupled with better educational status of the patients, urban residents was quoted to enable similar exposure to the case and thereby reduce the bias. Medical student's perception study found that under faculty supervision $70 \%$ were having satisfactory levels of conduction examination. ${ }^{8}$

Hesitancy of male interns to perform coupled with refusal by patients was felt as reduction in the opportunity for the interns to perform the procedures.

\section{Conclusion}

There is a perceived bias towards female gender as observed while learning obstetrics \& gynecology in comparison to male despite no observed difference during their learning exposures. Presence of faculties was found to facilitate equal opportunity across both the groups.
The patient characteristics and preferences, presence of people around the interns have had their influences upon the learning patterns among the interns.

\section{Limitations}

There were more female interns than male interns which could have led to a bias in favor of female gender towards the learning experiences.

\section{Acknowledgement}

I sincerely thank all the interns who had participated in the study.

\section{Conflict of Interest None declared}

\section{References}

1. Hamberg K, Risberg G, Johansson EE, Westman G. Gender Bias in Physicians' Management of Neck Pain: A Study of the Answers in a Swedish National Examination. J Womens Health Gend Based Med. 2002;11(7):653-66.

2. Risberg G, Hamberg K, Johansson EE. Gender perspective in medicine : a vital part of medical scientific rationality. A useful model for comprehending structures and hierarchies within medical science. 2006;5:2-6.

3. Racz JM, Srikanthan A, Hahn PM, Reid RL. Gender Preference for a Female Physician Diminishes as Women Have Increased Experience With Intimate Examinations. 2008.

4. Emmons SL, Adams KE, Nichols M, Cain J. The Impact of Perceived Gender Bias on Obstetrics and Gynecology Skills Acquisition by Third-Year Medical Students. Acad Med. 2004;79(4):326-32.

5. Guidelines for Conducting a Focus Group. 2005;1-13.

6. Flynn NO, Rymer J, Wass V. Women' s attitudes to the sex of medical students in a gynaecology clinic : cross sectional survey Commentary : Patients as partners in medical education. 2002;325(September):683-4.

7. Powell HS, Bridge J, Eskesen S, Estrada F, Laya M. Medical Students' Self-Reported Experiences Performing Pelvic, Breast, and Male Genital Examinations and the Influence of Student Gender and Physician Supervision. 2006;81(3):286-9.

8. Alam K, Safdar CA, Munir TA, Ghani Z. Original Article Teaching Obstetrics And Gynaecology To Male Undergraduate Medical Students : Student' S Perception. 2014;26(4):539-42. 